\section{Aspectos do cenário atual da reabilitação profissional no Brasil: avanços e retrocessos}

\author{
Aspects of the current workers' rehabilitation \\ scenario in Brazil: strides and setbacks
}

\author{
Aspectos de la perspectiva actual de la \\ rehabilitación profesional en Brasil: avances y \\ retrocesos
}

Cristiano Barreto de Miranda 1

doi: 10.1590/0102-311X00218717

\section{Resumo}

A reabilitação profissional brasileira incorporou recentemente mudanças nas concepções e princípios que a regem, ampliou-se o conceito de incapacidade baseado no modelo biopsicossocial de saúde, como também adotou-se a abordagem territorial e práticas intersetoriais, com vistas a fornecer subsídios para a implementação de um modelo integrado e intersetorial de reabilitação profissional. Entretanto, esses avanços não adentraram o campo da prática e encontram-se ameaçados frente a atual conjuntura politica do país. Este artigo discute o cenário atual do programa de reabilitação profissional do Instituto Nacional de Seguro Social (INSS), apresenta os avanços nos pressupostos teóricos que o norteiam e as preocupações que a reabilitação profissional enfrenta em virtude das recentes medidas que reforçam o caráter biomédico e de política compensatória que conduziu o programa ao longo dos anos, além de sinalizar uma eminente privatização desse serviço/direito previdenciário. Sugere-se que a reabilitação profissional vivencia um panorama de incertezas e preocupações, intensificado pelo processo de enfraquecimento institucional do INSS. Desse modo, as rápidas alterações realizadas na estrutura do INSS e no programa de reabilitação profissional prejudicaram as conquistas que fomentaram o início do desenvolvimento de um programa de reabilitação profissional integral e intersetorial, a fim de favorecer um retorno real e saudável ao trabalho.

Reabilitação; Saúde do Trabalhador; Previdência Social

\author{
Correspondência \\ C. B. Miranda \\ Faculdade de Saúde Pública, Universidade de São Paulo. \\ Av. Dr. Arnaldo 175, São Paulo, SP 03178-200, Brasil. \\ cristianobm@usp.br \\ 1 Faculdade de Saúde Pública, Universidade de São Paulo, São \\ Paulo, Brasil.
}




\section{Introdução}

A reabilitação profissional brasileira, presente na legislação previdenciária, tem mais de setenta anos de funcionamento, sendo caracterizada por ajustes e "desajustes" ao longo de sua trajetória histórica. Apesar desse percurso, a reabilitação de trabalhadores no país continua a ser um desafio complexo no campo da saúde pública ${ }^{1}$, particularmente, na área da saúde do trabalhador. O modelo de política compensatória adotado pelo Instituto Nacional do Seguro Social (INSS) tem sido insuficiente para favorecer o retorno real e saudável de trabalhadores com incapacidade para o mercado de trabalho por meio do serviço de reabilitação profissional 2.

Por conta desse cenário, em 2014 a Diretoria de Saúde do Trabalhador do INSS (DIRSAT-INSS), criada em 2009 pelo Decreto no 6934/09 3, colocou em consulta pública uma proposta de reabilitação profissional intitulada Reabilitação Profissional: Articulando Ações em Saúde do Trabalhador e Construindo a Reabilitação Integral 4, no intuito de reunir contribuições de pesquisadores e da sociedade para a construção coletiva de um modelo de reabilitação profissional integrado e intersetorial no país.

Baseando-se nessa iniciativa, foram incorporadas algumas mudanças nas concepções e princípios que regem o serviço de reabilitação profissional, bem como subsídios para iniciar o desenvolvimento de um modelo integrado e intersetorial. Assim, ampliou-se o conceito de incapacidade com base no modelo biopsicossocial de saúde e introduziu-se a abordagem territorial e de práticas intersetoriais, como também reconheceu-se a necessidade de equipes multidisciplinares no processo de reabilitação profissional. Esses primeiros avanços foram inseridos em um documento que fundamenta e preconiza as estratégias e ações que orientam os trabalhadores do INSS envolvidos com a reabilitação profissional, intitulado de Manual Técnico de Procedimentos da Área de Reabilitação Profissional, atualizado em 20165 .

Desse modo, o serviço de reabilitação profissional sinalizou, nesses últimos cinco anos, o intento de construção de um modelo teórico conceitual com possível rompimento das ações de caráter biomédico em suas práticas. Entretanto, os esforços realizados para a introdução dessas mudanças não foram capazes de romper com a macroestrutura hierárquica de ordem cultural, histórica e conceitual do INSS, em que se verifica um distanciamento cada vez maior do papel da Previdência Social dos pressupostos da Seguridade Social. Nesse aspecto, as parciais medidas progressistas que foram publicadas em 2016, no intuito de fortalecer o debate e desenvolvimento de um serviço integral e intersetorial para o Programa de Reabilitação Profissional do INSS, foram revogadas com a publicação da atualização do Manual Técnico de Procedimentos da Área de Reabilitação Profissional, em fevereiro de 20186. Nessa nova versão, reduziu-se o documento a uma descrição de normas e procedimentos do programa de reabilitação profissional, excluindo os pressupostos teóricos iniciados no manual anterior, com reforço das ações de características puramente biomédicas baseadas em uma lógica de assistência insuficiente e precária, as quais foram exaustivamente criticadas por especialistas na área de saúde do trabalhador ao longo dessas últimas duas décadas.

Destarte, este ensaio pretende apresentar aspectos do cenário atual do Programa de Reabilitação Profissional do INSS, que após indicar uma possível construção de um modelo teórico integral, retrocedeu com a permanência de medidas ineficientes que dificultam o retorno ao trabalho. Assim, este texto incorpora as discussões recentes a respeito da reabilitação profissional articuladas no âmbito acadêmico e no conjunto da sociedade, principalmente, nos debates pautados pelos sindicatos dos trabalhadores do INSS.

Na primeira parte do texto, relata-se brevemente o histórico do programa de reabilitação profissional do INSS, com destaque aos principais marcos e características do serviço ao longo dos anos. Em seguida, apresentam-se os novos pressupostos teóricos incluídos no programa de reabilitação profissional em 2016, os quais aproximam esse serviço do campo da Saúde do Trabalhador. Por fim, tecemse algumas reflexões sobre as transformações ocorridas no último ano, que afetaram a reabilitação profissional e que prejudicaram as iniciativas em desenvolver um programa integral e intersetorial. 


\section{(Des)ajustes da reabilitação profissional no Brasil: breve histórico}

A retrospectiva histórica da reabilitação profissional no Brasil já foi descrita e analisada detalhadamente por diferentes autores $2,7,8$, contudo, torna-se importante apontar alguns marcos dessa história para fundamentar este ensaio, como também, possibilitar uma maior compreensão do atual momento vivenciado pela reabilitação profissional no país. Em linhas gerais, as ações desenvolvidas pelo programa de reabilitação profissional estiveram fortemente conectadas às questões macroestruturais do sistema previdenciário brasileiro, que historicamente está inserido em uma lógica economicista e burocrática com destaque ao caráter assistencialista de seus serviços 8 .

A criação dos serviços de reabilitação profissional no Brasil ocorreu durante o Governo Getúlio Vargas por meio do Decreto-Lei no 7.036, de 10 de novembro de 1944, cujas práticas eram executadas pelas Caixas de Aposentadoria e Pensões (CAPs) e pelos Institutos de Aposentadorias e Pensões (IAPs). Nesse período, apenas as classes assalariadas urbanas tinham acesso ao serviço de reabilitação profissional, cuja função era de readaptação profissional e de reaproveitamento do empregado acidentado, com base em uma visão de saúde sob a perspectiva da Medicina do Trabalho, com valorização dos aspectos biológicos e individuais do sujeito 5 .

Um marco importante que representou a institucionalização do serviço de reabilitação profissional como atribuição do Seguro Social foi a Lei Orgânica da Previdência Social (Lei no 3.807 de 1960) 9. Por meio dessa legislação, as instituições previdenciárias tinham o dever de executar as atividades de reabilitação profissional. Além disso, o governo se responsabilizou com gastos de administração e recursos humanos, e também instituiu centros especializados - Centros de Reabilitação Profissional (CRP) - responsáveis pela prestação dos serviços de reabilitação profissional. Para Takahashi ${ }^{7}$, tais centros se expandiram na lógica securitária de recuperação para o emprego, que trazia em seu bojo a ideia de cidadania regulada pelo emprego, ou seja, o valor do indivíduo é determinado pelo lugar em que ele se encontra na estrutura produtiva. Assim, a revelar o caráter meritocrático e excludente na concessão dos benefícios previdenciários.

A década de 1960 também trouxe outros registros relevantes no processo de consolidação da reabilitação profissional, sendo eles, a estatização do Seguro Acidente de Trabalho (SAT), que se tornou a principal fonte permanente de custeio da reabilitação profissional, porém a cargo exclusivamente do empregador; e a unificação dos Institutos de Aposentadoria e Pensões, com a criação do Instituto Nacional de Previdência Social (INPS), que possibilitou, anos seguintes, a inserção de outras categoriais profissionais contempladas pelo serviço, bem como, permitiu a expansão das atividades de reabilitação profissional em outros lugares do território nacional 8. Ademais, destaca-se a criação da Comissão Permanente de Reabilitação Profissional da Previdência Social, cuja função era voltada ao planejamento, coordenação e fiscalização das ações do serviço de reabilitação profissional em todo o país 2. Por outro lado, não houve a preocupação por parte da Previdência em explicitar o significado e, tampouco, quaisquer procedimentos ligados aos serviços de reabilitação profissional, que se caracterizavam apenas como um programa de prevenção de acidentes do trabalho 2 .

Nas décadas de 1970 e 1980, o serviço de reabilitação profissional foi marcado por forte investimento em sua infraestrutura e de pessoal. Houve a expansão de grandes CRPs e de suas unidades menores, os chamados Núcleos de Reabilitação Profissional (NRPs), ambos do INPS e, anos depois, do INSS 2. Ocorreu também a disponibilidade de recursos terapêuticos por meio de uma equipe multiprofissional de saúde especializada e atividades de profissionalização com equipe técnica qualificada 5 . No entanto, os centros tinham forte tendência hospitalocêntrica, com uma atuação fragmentada, sem articulação com os órgãos assistenciais e órgãos fiscalizatórios das condições de trabalho, sem contar, a desarticulação com o próprio corpo pericial do INPS 2,8. Cabe ressaltar, ainda, a atuação limitada dos centros e núcleos de reabilitação às questões administrativas, pois, embora tivessem intervenções sobre as restrições causadas pela incapacidade, tornavam-na parte do sistema regulador das finanças previdenciárias, sem nenhuma intervenção sobre as condições de trabalho 2 .

Ao final da década de 1980 e início da de 1990, o país passou por uma forte crise fiscal que dificultou a reinserção do trabalhador ao mercado de trabalho. Ao mesmo tempo, o modelo de atenção à saúde realizado pelo serviço de reabilitação profissional era insuficiente frente à mudança do processo produtivo, que ocasionou um novo quadro de morbidade dos trabalhadores: a coexistência de acidentes de trabalho típicos e as doenças ocupacionais de evolução crônica e de forte sofrimento 
psíquico 2,5. Além dessas considerações, o cenário político do país passava por profundas transformações, particularmente por um processo de redemocratização após um longo período de regime ditatorial. Foi um momento marcado por fortes mobilizações sociais com destaque ao movimento sindical e sanitário 10 .

Como culminância desse período, foi promulgada a Constituição Federal de 1988, que instituiu um novo modelo de Seguridade Social, formada pelo tripé Saúde, Assistência e Previdência Social, regida por princípios de universalidade e equidade. O movimento social da Reforma Sanitária possibilitou que na Constituição o Estado se responsabilizasse em garantir o acesso à saúde para toda a população brasileira. Assim, foi criado o Sistema Único de Saúde (SUS), um sistema unificado, regionalizado, de acesso universal e integral, gerenciado pelo Ministério da Saúde, que ficou responsável por executar todas as ações em saúde, entre elas a Saúde do Trabalhador 10.

Por conseguinte, esse cenário de mudanças começou a adentrar na reabilitação profissional. Inicialmente, em 1992, foi instituída a Comissão Executiva Interministerial de Saúde do Trabalhador, que ao avaliar o serviço previdenciário de reabilitação profissional realizou inúmeras críticas ao modelo, propondo a descentralização e a reavaliação das metodologias empregadas, bem como reforçou a necessidade de pactuação com áreas da Saúde, do Trabalho, da Educação e da Ação Social. No ano seguinte, houve também a proposta de criação do Centro Integrado de Atenção em Saúde do Trabalhador, com a participação do Ministério do Trabalho, da Previdência Social e do SUS 8 .

Entretanto, esse conjunto de aspirações não foi capaz de vencer a lógica conservadora, burocrática e economicista da Previdência, representada por dirigentes que percebiam seus interesses corporativos ameaçados. Desse modo, rejeitou-se a transferência da reabilitação profissional para o SUS, com isto, excluiu-se a possibilidade do serviço de reabilitação profissional se tornar de acesso universalizado 7 . Assim, houve mudanças na organização dos serviços e na conduta de concessão de benefícios da Previdência Social por meio da Lei no 8.213, de 1991. Para Takahashi \& Iguti 8, essas novas alterações estão vinculadas às diretrizes macropolíticas e macroeconômicas neoliberais de redução de políticas públicas. Como resultado, foi implantado um Plano de Modernização da Reabilitação Profissional, que representou redução do modelo assistencial dos serviços de reabilitação profissional, eliminação das atividades terapêuticas, de recuperação e de ampliação da capacidade laborativa.

De fato, houve um desmonte do serviço de reabilitação profissional representado pela redução dos investimentos, desativação dos CRPs e NRPs e decomposição das equipes multidisciplinares, com descentralização dos serviços para as agências de benefícios do INSS. Assim, com o passar dos anos, o serviço de reabilitação profissional foi sendo reduzido e alterado, transformando-se em um subprograma de perícias médicas ${ }^{8}$ por meio da implantação, em 2001, do Programa Reabilita, modelo predominante nos dias atuais, cujo objetivo é a habilitação do trabalhador em outra atividade por intermédio de cursos e treinamentos, sob a responsabilidade institucional de orientadores profissionais e do perito médico 5 , com as seguintes funções básicas: avaliação e definição da incapacidade laborativa; orientação e acompanhamento do programa profissional; articulação com a comunidade; e pesquisa de fixação no mercado de trabalho ${ }^{5}$. Esse modelo tem sido alvo de diversas críticas de estudiosos na área da saúde do trabalhador, pois é reducionista, compensatório, fragmentado, desarticulado com outras políticas públicas e de saúde, assim como, não favorece o retorno real e saudável ao trabalho $2,7,9$.

Em 2009, foi criada a DIRSAT-INSS, que entre os diversos objetivos, tem o intuito de aperfeiçoar o programa de reabilitação profissional 5. Entretanto, as ações dessa diretoria têm se mostrado restritas às questões técnicas com poucas alterações na estrutura e concepção do serviço de reabilitação profissional. Em 2010, o INSS publicou a Resolução no 118, que autorizou a realização de acordos de cooperação técnica entre a reabilitação profissional e entidades públicas ou privadas para a prestação de alguns serviços, entre eles, atendimento assistencial especializado; avaliação e elevação do nível de escolaridade; avaliação e treinamento profissional; e promoção de cursos profissionalizantes 5 .

Em 2011, o Poder Executivo aprovou a Política Nacional de Segurança e Saúde no Trabalho (PNSST) 11, com a inclusão da reabilitação profissional como um dos princípios estruturantes. Todavia, sem possibilitar, na prática, mecanismos e investimentos que promovessem impactos significativos na melhoria do serviço de reabilitação profissional. Em 2012, os ministérios da Previdência Social, do Trabalho e Emprego, da Saúde e do Planejamento, Orçamento e Gestão, por meio da Portaria Interministerial no 323 12, instituíram o Grupo de Trabalho responsável pela avaliação e proposição de 
Políticas de Saúde e Segurança no Trabalho (GTSST). Esse GT elegeu os temas do modelo pericial do INSS e a reabilitação profissional como prioritários para discussão.

Nesse sentido, a partir de 2013, iniciou-se um movimento interno no INSS para tentar alinhar o serviço de reabilitação profissional com a Saúde do Trabalhador ${ }^{5}$. Embora essa aproximação tenha se traduzido apenas na perspectiva teórica, ela revela um passo importante para fomentar o desenvolvimento de uma proposta de modelo integrado e intersetorial de reabilitação profissional, que será bem detalhado no próximo tópico deste ensaio.

\section{Aproximação da reabilitação profissional com a saúde do trabalhador: a caminho de um modelo integral?}

A compreensão da complexidade da incapacidade humana, particularmente, aquela adquirida no trabalho, configura-se como uma das principais questões levantadas na literatura para o desenvolvimento das ações de um programa de reabilitação de trabalhadores 13,14. Assim, a ausência de um modelo de avaliação da incapacidade caracterizado por uma análise que englobe uma visão integralizada do indivíduo e do seu coletivo tornou-se uma das principais críticas ao serviço de reabilitação profissional do INSS ao longo dos anos 13,15. Além da necessidade de um modelo teórico conceitual da reabilitação profissional no país, diversos autores 2,7,8,13,14 elencam que tal modelo deve estar alinhado ao campo da saúde do trabalhador. Com isso, reportam sobre a importância da articulação do INSS com outras instituições públicas, especialmente com o Ministério da Saúde. Para Maeno \& Vilella 2, é essencial que essa articulação entre os setores da saúde e da Previdência Social compartilhe das mesmas concepções de saúde, incapacidade e reabilitação profissional.

No entanto, o caminho para iniciar o desenvolvimento de um serviço de reabilitação profissional que considere uma visão integrada do processo de reabilitação torna-se uma trajetória árdua, desafiadora e de contramão com a lógica economicista do modelo de seguro presente na macroestrutura do sistema previdenciário brasileiro, em que privilegia a restrição de benefícios em detrimento da garantia de direitos constitucionais adquiridos. Sem contar a necessidade de romper, especificamente, com a rigidez da estrutura hierárquica do INSS que tem uma cultura institucional distante dos conceitos de Seguridade Social, assim como, rever o modelo pericial para a concessão dos benefícios. Além de superar a falta de integração e articulação da Previdência Social com outros ministérios 7,16.

Em relação a esses desafios, o GT Interministerial em Segurança e Saúde no Trabalho, em reunião no dia 03 de dezembro de 2013 17, iniciou o debate sobre a proposta da DIRSAT referente ao projeto de reabilitação profissional integral e articulado com a saúde do trabalhador. Nessa reunião foram levantadas discussões a respeito da necessidade de: mudar a visão da reabilitação profissional como um processo final de intervenção sobre a incapacidade; tornar o serviço ágil com avaliação multidisciplinar precoce em articulação intersetorial e cobertura previdenciária adequada; tornar o trabalhador sujeito do processo de reabilitação profissional; buscar abordagens para criar mecanismos de mudanças de condições de trabalho; entre outros. Também foi registrada uma proposta de publicação de edital-convite em conjunto com os ministérios da Previdência Social, da Saúde e do Trabalho e Emprego para incentivar o desenvolvimento de programas integrados de prevenção de incapacidades e de reabilitação profissional 17 .

Além disso, a representante da Fundação Jorge Duprat e Figueiredo (FUNDACENTRO) encaminhou um documento para o $e$-mail do GT no qual propôs diretrizes para uma Política de Reabilitação Profissional. Cabe esclarecer que esse documento, cuja denominação era Proposta de Diretrizes para uma Política de Reabilitação Profissional 18, foi elaborado em agosto de 2013 pela FUNDACENTRO e colaboradores envolvidos com a temática da reabilitação profissional, com base nas discussões e eventos realizados desde 2007 por esta instituição. Assim, o documento elaborado pela FUNDACENTRO se caracteriza como uma das primeiras propostas de construção coletiva que detalhou a situação do serviço de reabilitação profissional após a primeira década de 2000, com apontamento dos principais problemas e definição de propostas para discussão. A ausência de um modelo teórico conceitual para fundamentar o programa de reabilitação profissional e a atual predominância das características do modelo biomédico foram problemas diagnosticados. Além disso, ressaltou-se a importância da não dissociação entre o serviço da perícia e o serviço de reabilitação profissional, pois a perícia é a porta 
de entrada para a reabilitação profissional e torna-se necessário um entendimento comum sobre a incapacidade, sendo avaliada em um contexto multidisciplinar e concebida baseando-se em uma perspectiva biopsicossocial 18 .

Um fato curioso, ainda sobre a reunião do GTSST, foi a postura dos representantes do Ministério do Planejamento, os quais não contribuíram com as discussões (não há menção na Ata sobre a colaboração deles ao debate) com a justificativa de que precisariam discutir internamente os assuntos em questão entre os representantes do Ministério da Previdência Social e do INSS para depois debater as conclusões com o GTSST. Essa atitude revela a maneira histórica de como o INSS desenvolve suas ações desintegradas com outros setores, além de, muitas vezes, não permitir o acesso ou fornecer informações parciais de seus serviços, particularmente as informações ligadas ao programa de reabilitação profissional. Com isso, não se tem registros, ou não estão de fácil acesso, sobre o que foi discutido internamente no INSS sobre as questões levantadas pelo GTSST, não se sabe se houve discussão sobre incentivo de práticas integradoras de reabilitação profissional, tampouco se as propostas de diretrizes políticas para a reabilitação profissional elaborada pela FUNDACENTRO foram debatidas.

Desse modo, a DIRSAT elaborou inicialmente o projeto Reabilitação Profissional: Articulando Ações em Saúde do Trabalhador e Construindo A Reabilitação Integral 19, sem considerar os apontamentos e discussões levantados no GTSST. Logo, o projeto apresentava discussões gerais e parciais do processo de reabilitação profissional sem apresentar soluções concretas aos problemas enfrentados pelo programa, bem como não apresentou um modelo teórico para fundamentar as ações da reabilitação profissional. Por outro lado, colocou o projeto em consulta pública, em fevereiro de 2014. Todavia, cabe ressaltar que o documento formulado pela FUNDACENTRO reunia a contribuição coletiva de diversos profissionais e pesquisadores em âmbito nacional, o qual expressava uma construção aprofundada de análise da reabilitação profissional. Assim, a DIRSAT poderia ter apoiado o documento já existente e iniciado uma proposta, de fato, integradora.

Durante os quatro anos destinados a implementar a primeira etapa do projeto de reabilitação integral, algumas ações do plano de trabalho foram realizadas. Em relação à pactuação intersetorial, foi registrado o fortalecimento da parceria do INSS com o Ministério da Educação por intermédio do Programa Nacional de Acesso ao Ensino Técnico e Emprego (PRONATEC), firmado em dezembro de 2012, que objetivou fornecer cursos referentes à qualificação profissional 20. Para Santos \& Esquerdo 21, por meio dessa parceria houve uma ampliação significativa da oferta de cursos e maior número de vagas disponibilizadas em diversas áreas. Em Ata da 28a Reunião Ordinária do Conselho Nacional de Previdência Social (CNPS) 22, ocorrida em 30 de junho de 2016, em que se discutiu o programa de reabilitação profissional, foi citada a parceria firmada pelo INSS com o Ministério do Trabalho valendo-se do Serviço de Intermediação de Mão de Obra (IMO), que visa a colocar trabalhadores por meio de vagas captadas junto a empregadores, assim, a promover o encontro de oferta e demanda de trabalho. Porém, não se detalhou como foi realizada a articulação entres esses setores.

Outra pactuação acordada pelo INSS foi com a Federação das Indústrias do Estado de São Paulo (FIESP) e o Serviço Nacional de Aprendizagem Industrial (SENAI) 23, ocorrida em outubro de 2017, e renovada em janeiro de 2018, com o objetivo de promover a reabilitação dos segurados por meio de 500 bolsas de estudo integral em qualificação profissional em diversas áreas tecnológicas. Essa parceria foi inicialmente questionada pelos trabalhadores do INSS envolvidos com a reabilitação profissional, pois foi firmada sem nenhum diálogo prévio. Para a Federação Nacional dos Sindicatos dos Trabalhadores em Saúde, Trabalho, Previdência Social e Assistência Social (FENASPS) 24, essa cooperação técnica entre o INSS, a FIESP e o SENAI poderia possibilitar maior predominância dos interesses patronais sobre os interesses dos trabalhadores participantes do programa de reabilitação profissional.

Um importante avanço no desenvolvimento do projeto integral de reabilitação profissional, sem dúvidas, foi a reorientação das diretrizes teóricas, técnicas e normatizadoras por meio da promulgação do Decreto-Lei no 8.725/2016 25 que instituiu a Rede Intersetorial de Reabilitação Integral, e da atualização do Manual Técnico de Procedimentos da Área da Reabilitação Profissional 5, ambas ocorridas no ano de 2016. Logo, pela primeira vez, o programa de reabilitação profissional iniciou a construção de um modelo teórico para fundamentar suas ações, ancorada em uma legislação específica que valoriza as ações integradas de políticas públicas. 
O Decreto-Lei no 8.725/2016, de 27 abril de 2016 25, foi um marco importante para iniciar o debate na reorientação da reabilitaçaõ profissional, pois instituiu a Rede Intersetorial de Reabilitação Integral para pessoas com deficiências, com vistas à integração e à articulação permanente entre serviços e ações das políticas de saúde, previdência social, trabalho, assistência social, educação, entre outros. A partir desse decreto, o Estado reconheceu que a eficácia da reabilitação profissional só é possível por intermédio de uma política transversal e intersetorial, que envolva uma rede integrada e articulada de ações e serviços que englobe todos os níveis de assistência à saúde do trabalhador:

"Para os efeitos deste Decreto, considera-se reabilitação integral o conjunto de serviços e ações integradas de políticas públicas que combinem atenção e assistência integrais à saúde, à reabilitação profissional e à reinserção social, para o desenvolvimento de potencialidades, talentos, habilidades e aptidões físicas, cognitivas, sensoriais, psicossociais, atitudinais, profissionais e artísticas que contribuam para a conquista da autonomia da pessoa com deficiência e de sua participação social em igualdade de condições e oportunidades com as demais pessoas, de modo a propiciar a participação do indivíduo nos ambientes profissional, social, cultural e familiar" 25.

Já o Manual Técnico de Procedimentos da Área da Reabilitação Profissional 5, incorporou elementos teóricos primordiais que se configuram como avanços conceituais na construção de uma reabilitação profissional integral alinhada com a saúde do trabalhador. Um dos principais progressos diz respeito à ampliação do conceito de incapacidade humana com base no modelo biopsicossocial de saúde proposto pela Classificação Internacional de Funcionalidade, Incapacidade e Saúde (CIF) 26. Nesse modelo, a incapacidade é um termo genérico para deficiências, limitações de atividades e restrições de participação, indicada por aspectos negativos da interação entre o indivíduo (com uma condição de saúde) e seus fatores contextuais (fatores ambientais e pessoais) 27 . Assim, ultrapassa uma concepção de incapacidade restrita aos aspectos físicos e começa a se considerar também os elementos sociais, políticos e psíquicos envolvidos no desenvolvimento da incapacidade. Desse modo, o modelo teórico proposto pela CIF passou a ser recomendado nas ações da reabilitação profissional, particularmente na avaliação da incapacidade laborativa:

"Ressalta-se que o conceito de funcionalidade da CIF permite aproximar, para fins de avaliação, situações distintas como doenças, deficiências e incapacidades ao descrevê-las como restrição de participação social. Isso é, não importa as causas das doenças, das deficiências e das incapacidades e, sim, as consequências de tais situações para a vida das pessoas. Há um reconhecimento de que os fatores ambientais e barreiras sociais impedem a plena participação na sociedade das pessoas que apresentam uma diversidade corporal. (...) A avaliação do potencial laborativo e toda a condução da Reabilitação Profissional deve considerar os aspectos da perspectiva biopsicossocial preconizada na CIF..." 5.

Outro avanço teórico está relacionado ao reconhecimento da contribuição da reabilitação profissional na promoção à saúde e prevenção de adoecimento e acidentes nos ambientes e processos de trabalho, valendo-se de ações integradas de vigilância em saúde e do fomento ao controle social. Além disso, ressalta-se também o reconhecimento do território como espaço de referência para a reabilitação profissional, tanto em sua dimensão complexa, culturalmente regionalizada, quanto ao acesso de bens e serviços essenciais para a composição de rede. Com isso, auxiliar na compreensão do trabalhador como sujeito e a totalidade em que ele está inserido ${ }^{5}$. Acrescenta-se também que a abordagem territorial favorece a vigilância em saúde e a intersetorialidade:

"...o conhecimento do território poderá fornecer elementos para vigilância em saúde, a partir da notificação, ou troca de informações. O território emerge como lócus estratégico para se realizar a articulação entre as políticas públicas, a participação e o controle social. A intersetorialidade emerge como uma estratégia de gestão focada na articulação entre as diversas políticas públicas (saúde, assistência, mobilidade, educação, direitos humanos, trabalho e renda, previdência) e na otimização das estruturas humanas, físicas e institucionais disponiveis" 5.

Nesse sentido, a intersetorialidade, como pressuposto fundante, torna-se a principal estratégia para atingir o objetivo de tornar a reabilitação profissional um programa integral. Uma vez que é necessária a articulação entre as políticas macroeconômicas que privilegiem a vida, o trabalho, a saúde e o meio ambiente 5 . Sem contar que o campo de saúde do trabalhador, onde a reabilitação profissional está inserida, é genuinamente interdisciplinar e exige a gestão de ações intersetoriais por meio de equipes multidisciplinares:

"A Reabilitação Profissional do INSS deve também realizar uma ampla articulação com os diversos setores que compõem a sociedade e as administrações públicas e privadas, no âmbito dos entes federados, na perspectiva de articular uma rede de serviços que busque e implemente soluções para os grandes desafios que a (Re) 
habilitação Integral impõe (...) é fundamental para a Reabilitação Profissional pautar-se na interdisciplinaridade, atuação de equipes multiprofissionais e intersetorialidade (...). Práticas interventivas se fazem necessárias na busca de utilizar os diversos saberes, conhecimentos e articulação com as políticas públicas setoriais a fim de promover a garantia de direitos sociais de forma ampliada" 5 .

Ao mesmo tempo, há uma série de contradições por parte do INSS que não favorecem a viabilização de um modelo integral de reabilitação profissional. Uma das primeiras contradições é a publicação isolada e desarticulada do manual que fundamenta o modelo de reabilitação integral, o qual considera pressupostos intersetorias e interdisciplinares, mas que não dialoga com outros setores. Ou seja, propõem-se um modelo de integralidade com base em um documento que não é integrado com instâncias da assistência social, da saúde e do trabalho, por exemplo. Além disso, havia um projeto elaborado pela FUNDACENTRO, que inclusive apontou uma série de problemas e propostas para discussão sobre a reabilitação profissional, mas que não foi considerado nem apoiado pela DIRSAT.

Embora tenha sido ampliada a concepção de incapacidade e reconhecida a importância do modelo biopsicossocial na avaliação do potencial laborativo, não houve nenhuma menção no manual de reabilitação profissional sobre alguma alteração de fluxo pericial que possibilite a avaliação multidisciplinar precoce, tampouco sobre a redefinição do papel da perícia médica, a qual utiliza o conceito de incapacidade baseado somente na Classificação Internacional de Doenças (CID), que tem uma visão biomédica, com uma perspectiva contrária à abordagem do modelo biopsicossocial. Já que a perícia é a porta de entrada para o serviço de reabilitação profissional, torna-se fundamental conceber a incapacidade sobre uma perspectiva comum. Ademais, conforme as diretrizes propostas pela FUNDACENTRO 18, o sistema de avaliação das perícias deve ser compatível com os interesses da Seguridade Social, deste modo, o modelo biopsicossocial oferece uma ampliação do conceito de incapacidade, pois além da doença inclui aspectos de funcionalidade, de suporte familiar e social, e as exigências do trabalho. Assim, o modelo biopsicossocial permite que durante uma avaliação pericial se enxergue o indivíduo em sua totalidade, como pessoa inserida em um contexto político e social 26.

Outra grande incoerência do INSS é a ausência de discussão de ações para intervir nas condições de trabalho. Como favorecer a prevenção de riscos ocupacionais e a promoção à saúde nos ambientes e processos de trabalho sem apresentar estratégias concretas que promovam mudanças no trabalho? O INSS continua sem discutir a importância da análise da atividade de trabalho, por exemplo. Há tempos sabe-se que o trabalhar consiste em um conjunto de regulações contextualizadas, por isto, para se entender o que é trabalho torna-se necessário observar e analisar como cada indivíduo desenvolve sua atividade em situações reais, em seu contexto particular, a fim de se resolver os problemas recorrentes e cotidianos durante o processo de trabalho, os quais, muitas vezes, são a gênese dos ciclos de acidentes e adoecimento no trabalho 28.

Por certo, as medidas progressistas adotadas nesses últimos cinco anos não foram capazes de romper com questões internas de ordem cultural, estrutural e conceitual do INSS, as quais estão historicamente consolidadas e intimamente relacionadas com os pressupostos neoliberais de valorização dos interesses financeiros em detrimento das políticas sociais. De acordo com Teixeira 16, a "americanização perversa” do sistema previdenciário no Brasil vem se desenvolvendo com muita rapidez, assim, ampliando os espaços para os sistemas previdenciários privados e restringindo o papel do Estado em oferecer uma previdência social básica para os que mais necessitam. Desse modo, o que se observa é um distanciamento cada vez maior do INSS da concepção de Seguridade Social e uma aproximação íntima com a concepção de previdência social como seguro, obtendo as mesmas características das seguradoras privadas.

Com efeito, a continuação do projeto integral de reabilitação profissional se torna inviável, pois, desde o final de 2016, o INSS tem revogado as medidas que representaram avanços na reabilitação profissional, adotadas nesses últimos quatro anos. Para completar, em fevereiro de 2018 foi publicada uma atualização do Manual Técnico de Procedimentos da Área de Reabilitação Profissional 6, que adotou medidas opostas ao projeto que vinha sendo desenvolvido, com reforço do modelo biomédico nas ações de reabilitação profissional, representando, assim, um verdadeiro retrocesso neste serviço previdenciário. Alguns elementos que aceleraram tais retrocessos serão apresentados no próximo tópico deste ensaio. 


\section{Breves apontamentos sobre as alterações na estrutura do INSS: elementos de retrocesso no serviço de reabiltação profissional}

O serviço previdenciário de reabilitação profissional, como observado anteriormente, iniciou, a partir de 2013, um processo de reconhecimento dos pressupostos ligados à saúde do trabalhador para direcionar suas práticas, porém esse debate, apesar de ter sido realizado parcialmente, desarticulado de outros setores e sem ter adentrado o campo da prática propriamente dito, não foi aprofundado, ou melhor, foi interrompido. Havendo assim, a manutenção das características fragmentadas, de natureza compensatória e com ações sob a perspectiva do modelo biomédico na avaliação da incapacidade e no desenvolvimento das estratégias de reabilitação dos trabalhadores. De maneira resumida, a interrupção do desenvolvimento de um projeto integral para a reabilitação profissional, em meados de 2016, e o retorno de práticas anteriormente adotadas ocorreu em um contexto de profunda crise política e econômica no país (que se estende aos dias atuais), marcado pelos desdobramentos do processo de impedimento do Governo Dilma Rousseff e início do Governo Interino Michel Temer. É inquestionável que um ciclo de alterações e propostas de reformas já estava em curso, porém o Governo Temer tem sido marcado, explicitamente, por uma forte agenda política neoliberal, caracterizada por um pacote de medidas que minimizam ainda mais o papel do Estado na garantia de direitos, serviços e de proteção social, com o enfraquecimento das instituições estatais em todos os setores, inclusive o da Previdência Social, impactando os serviços previdenciários.

Desse modo, o cenário das políticas sociais no país vive um momento de incertezas e preocupações frente às medidas e reformas aprovadas (na verdade, com características de contrarreformas) no último ano. Uma das primeiras medidas adotadas pelo governo foi a promulgação da Emenda Constitucional no 95 29, em 2016, que estabeleceu um novo regime fiscal paras as despesas primárias do Governo Federal com duração de vinte anos e possibilidade de revisão - restrita ao índice de correção - em dez anos. Com isso, o gasto primário fica limitado por um teto definido pelo montante gasto no ano anterior reajustado pela inflação acumulada, medida pelo Índice Nacional de Preços ao Consumidor Amplo (IPCA). Assim, as regras desse novo regime fiscal não permitem o crescimento das despesas totais e reais do governo acima da inflação, mesmo havendo crescimento econômico e demográfico durante os próximos vinte anos 30. Em síntese, essa medida poderá potencializar o sucateamento das políticas sociais, principalmente as da saúde, educação e de assistência social. Com efeito, o Estado reduz seu papel de indutor do crescimento econômico e promotor do bem-estar social.

As implicações dessa política de austeridade já podem ser notadas em diversos setores. No tocante à Previdência Social, verificou-se a extinção do Ministério da Previdência Social, em 2016 31, cujas atividades foram transferidas para as pastas do Desenvolvimento Social e Agrário e da Fazenda. Assim, o Conselho Nacional de Previdência Complementar, a Câmara de Recursos da Previdência Complementar, o Conselho Nacional de Previdência Social, o Conselho de Recursos da Previdência Social e a Empresa de Tecnologia e Informações da Previdência Social (DATAPREV) foram transferidos para o Ministério da Fazenda 32. Apenas o INSS ficou sob a responsabilidade do Ministério do Desenvolvimento Social e Agrário 33. A extinção do Ministperio da Previdência Social pode ser considerada uma das primeiras ações na intensificação do processo de enfraquecimento institucional que o INSS tem vivenciado em sua história, com impactos em sua estrutura e, principalmente, na manutenção dos serviços prestados à população. Para a Associação Nacional dos Participantes de Fundos de Pensão (ANAPAR) 34 , colocar a Previdência Social sob a responsabilidade do Ministério da Fazenda é tratar a previdência somente pelo viés financeiro em detrimento das políticas sociais. Segundo a especialista em estudos sobre desigualdade social, Laura Tavares Soares, a mudança da Previdência para a Fazenda poderá trazer consequências sociais drásticas ao país 35. Além disso, vislumbra-se o reforço das concessões de benefícios pela lógica de restrição orçamentária e fiscal, bem como, da concepção dos benefícios baseando-se em uma visão assistencialista ao invés do entendimento como direito adquirido 36 .

Outra implicação do novo regime fiscal na Previdência é o fortalecimento das operações de revisão de benefícios concedidos, as chamadas operações "pente-fino", como medida para reduzir gastos com a máquina pública. Tais operações, pela própria nomenclatura, revela a maneira pejorativa pela qual o INSS trata o trabalhador adoecido por condições de trabalho cada vez mais precárias. Ou seja, essas operações reforçam a lógica de perícias concebidas como meio de encontrar possíveis trabalhadores fraudadores do sistema, em vez de permitir uma acurácia de investigação que priorize o 
entendimento do processo de adoecimento dos trabalhadores e se, de fato, ele terá direito de usufruir de algum benefício dentro da lógica de Seguridade Social 18.

Nessa mesma prerrogativa de austeridade, percebe-se a manutenção do serviço de reabilitação profissional dentro dos limites de procedimentos administrativos, preocupando-se apenas com a contenção de custos. A respeito disso, foram registradas mudanças com uma velocidade indescritível nos últimos meses, as quais não possibilitam a viabilidade da proposta de reabilitação integral. Foram alteradas conquistas recentes por intermédio de diversos documentos internos do INSS, os quais: extinguiu-se a equipe multidisciplinar para avaliação dos benefícios de longa duração 37; revogaram as nomeações e dispensaram os Representantes Técnicos das Superintendências Regionais 38; além de se desconsiderar os fatores socio-ocupacionais dos segurados e de se implementar o ato médico na reabilitação profissional 39, ou seja, a avaliação da elegibilidade dos casos em programa passou a ser feita somente pelo perito médico. Essas mudanças foram consolidadas na atualização do Manual de Procedimentos Técnicos da Área de Reabilitação Profissional em fevereiro de 2018 6, como mencionado anteriormente, e se caracterizam como medidas de retrocesso do serviço de reabilitação profissional pois retirou toda a discussão envolvida sobre um modelo de reabilitaçaõ profissional baseado em pressupostos biopsicossociais.

A avaliação da elegibilidade para o programa de reabilitação profissional apenas pelo perito médico não dá conta de compreender os fenômenos envolvidos no desenvolvimento da incapacidade para o trabalho, pois considerar apenas os elementos anátomo-fisiológicos não permite traçar o estabelecimento do desenvolvimento do nexo causal com o trabalho. O enfoque nos aspectos biomédicos não possibilita uma visão integrada do processo de reabilitação profissional, assim requer a interseção das ações psíquicas e socioprofissionais, a qual só é possível valendo-se de uma visão integrada e multiprofissional. Uma avaliação contínua e integrada permite entender e corroborar uma decisão segura quanto à constatação da incapacidade que justifique a concessão do serviço/benefício 18. Além disso, deixar de considerar pressupostos ligados à saúde do trabalhador é manter o processo de reabilitação de trabalhadores refém dos interesses patronais e à mercê das questões financeiras e econômicas, bem como, não favorece um retorno real e saudável ao trabalho.

Diante desses retrocessos, cabe mencionar a resistência dos trabalhadores envolvidos com a reabilitaçaõ profissional na luta por um serviço previdenciário que esteja ligado aos pressupostos da Seguridade Social. Aliás, a resistência dos servidores do INSS, fundada em um permanente conflito histórico com o órgão, tem sido um dos mecanismos que protegem a manutenção de políticas sociais na instituição. Em maio de 2017, os representantes da Federação Nacional dos Sindicatos dos Trabalhadores em Saúde, Trabalho, Previdência Social e Assistência Social (FENASPS) participaram de uma audiência pública na comissão de Direitos Humanos e Legislação Participativa (CDH) do Senado, onde denunciaram o desmonte progressivo dos serviços previdenciários de reabilitação profissional e do Serviço Social no INSS, com críticas à intervenção da Associação Nacional de Médicos Peritos (ANMP) no desenvolvimento das ações do órgão 40. A denúncia realizada teve como base a divulgação interna de uma minuta do INSS que propunha alterar o regime interno do instituto de 2009 (Portaria no 296), tendo como objetivo a extinção do serviço social e do serviço de reabilitaçaõ profissional da estrutura do INSS. Para a FENASPS e a Associação Nacional dos Servidores Públicos da Previdência Social e da Seguridade Social (ANASPS) 41, a retirada do serviço social implicaria diretamente a redução de acesso à política de previdência social e às demais políticas da Seguridade Social.

Em função da proposta de extinção dos serviços de assistência social e reabilitação profissional, os servidores realizaram diversos debates e mobilizações em âmbito nacional na luta pela manutenção destes serviços. Uma das manifestações mais expressivas foi a ocupação do Ministério do Desenvolvimento Social, quando foram apresentadas reivindicações ao ministro, dentre elas, a perda de autonomia técnica, ingerência da gestão atual da DIRSAT, esvaziamento das representações técnicas em âmbito regional e nacional etc. ${ }^{24}$. Além da ocupação, também houve a paralisação dos serviços de reabilitação profissional e serviço social em quase todos os estados do país. Após a intensa mobilização dos servidores, o Ministério do Desenvolvimento Social recuou da proposta de retirar o serviço social da estrutura do INSS. De fato, a história do serviço social na previdência tem sido uma história de luta pela garantia de direitos da classe trabalhadora. 


\section{Considerações finais}

A incorporação de pressupostos teóricos baseados no modelo biopsicossocial de saúde, da intersetorialidade e da noção de território no manual técnico da reabilitação profissional representara um grande passo para iniciar o percurso de um possível modelo teórico conceitual de reabilitação profissional no país. No entanto, foram mudanças desenvolvidas de maneira isolada, sem a integração com outros setores como, por exemplo, a saúde e assistência social. Com isso, sem transpor o campo teórico e não sendo capaz de romper com questões estruturais, culturais e hegemônicas consolidadas historicamente no INSS.

É evidente que não se pode desconsiderar as profundas dificuldades que o programa de reabilitaçaõ profissional do INSS sofria, e ainda sofre, como por exemplo, a falta de investimentos, o pouco número de recursos humanos, bem como práticas insuficientes na promoção do retorno ao trabalho. De fato, o sucateamento e a falta de investimentos no programa de reabilitação profissional tem sido uma tendência cada vez maior dentro do INSS.

As questões ligadas à reabilitação de trabalhadores tornaram-se ainda mais complexas e desafiadoras. Recentemente, observou-se a aprovação da reforma trabalhista que desconsiderou importantes conquistas e direitos historicamente alcançados, fazendo com que a possibilidade de uma saúde integral aos trabalhadores fique ainda mais difícil, porém, esta é uma discussão que cabe ser aprofundada posteriormente.

\section{Agradecimentos}

Às Professoras Dra. Frida Marina Fischer e Dra. Claudia Moreno pela oportunidade de escrita deste ensaio durante a disciplina de História e Política em Saúde do Trabalhador ofertada no curso de Pósgraduação em Saúde Pública, Faculdade de Saúde Pública, Universidade de São Paulo (FSP/USP). Agradeço especialmente à Professora Frida por todo incentivo para a produção e apoio neste ensaio

\section{Referências}

1. Lima MAG, Andrade AGM, Bulcão CMA, Mota EMCL, Magalhães FB, Carvalho RCP, et al. Programa de reabilitação de trabalhadores com LER/DORT do Cesat/Bahia: ativador de mudanças na Saúde do Trabalhador. Rev Bras Saúde Ocup 2010; 35:112-21.

2. Maeno M, Vilela RAG. Reabilitação profissional no Brasil: elementos para a construção de uma política pública. Rev Bras Saúde Ocup 2010; 35:87-99.

3. Brasil. Decreto no 6.934, de 11 de agosto de 2009. Aprova a estrutura regimental e o quadro demonstrativo dos cargos em comissão, das funções gratificadas e das funções comissionadas do INSS. Diário Oficial da União 2009; 12 ago. 
4. Ministério da Previdência Social. INSS abre consulta pública sobre reabilitação profissional. http://www.previdencia.gov.br/2014/02/ de-sua-colaboracao-inss-abre-consulta-publi ca-sobre-reabilitacao-profissionai/ (acessado em 08/Set/2017).

5. Instituto Nacional de Seguridade Social, Ministério da Previdência Social. Manual técnico de procedimentos da área da reabilitação profissional. Brasília: Ministério da Previdência Social; 2016

6. Instituto Nacional de Seguridade Social, Ministério da Previdência Social. Manual técnico de procedimentos da área da reabilitação profissional. Brasília: Ministério da Previdência Social; 2018.

7. Takahashi MABC. Incapacidade e Previdência Social: trajetória de incapacitação de trabalhadores adoecidos por LER/DORT no contexto da reforma previdenciária brasileira da década de 1990 [Tese de Doutorado]. Campinas: Faculdade de Medicina, Universidade de Campinas; 2006.

8. Takahashi MABC, Iguti AM. As mudanças nas práticas de reabilitação profissional da Previdência Social no Brasil: modernização ou enfraquecimento de proteção social? Cad Saúde Pública 2008; 11:2661-70.

9. Brasil. Lei no 3.807 , de 26 de agosto de 1960. Dispões sobre a Lei Orgânica da Previdência Social. Diário Oficial da União 1960; 5 set.

10. Mendes R, Dias EC. Da medicina do trabalho à saúde do trabalhador. Rev Saúde Pública 1991; 25:341-9.

11. Brasil. Portaria no 1.823 , de 23 de agosto de 2012. Institui a Política Nacional de Saúde do Trabalhador e da Trabalhadora. Diário Oficial da União 2012; 24 ago.

12. Brasil. Portaria Interministerial no 323 , de 11 de julho de 2012. Institui Grupo de Trabalho responsável pela avaliação e proposição de Políticas de Saúde e Segurança no Trabalho. Diário Oficial da União 2012; 12 jul.

13. Maeno M, Takahashi MABC, Lima MA. Reabilitação Profissional como política de inclusão. Acta Fisiatr 2009; 16:53-8.

14. Toldrá RC, Daldon MTB, Santos MC, Lacman $\mathrm{S}$. Facilitadores e barreiras para o retorno ao trabalho: a experiência de trabalhadores atendidos em um Centro de Referência em Saúde do Trabalhador - SP, Brasil. Rev Bras Saúde Ocup 2010; 35:10-22.
15. Simonelli AP, Camarotto JA, Bravo ES, Vilela RAG. Proposta de articulação entre abordagens metodológicas para melhoria do processo de reabilitação profissional. Rev Bras Saúde Ocup 2010; 35:64-73.

16. Teixeira AMP. Previdência Social no Brasil: da revolução passiva à contra-reforma [Tese de Doutorado]. Rio de Janeiro: Centro de Filosofia e Ciências Humanas, Universidade Federal do Rio de Janeiro; 2006.

17. Ministério da Previdência Social. Ata de reunião do Grupo de Trabalho de Política de Saúde e Segurança no Trabalho de 03 de dezembro de 2013. Brasília: Ministério da Previdência Social; 2013.

18. Fundação Jorge Duprat e Figueiredo. Proposta de diretrizes para uma política de reabilitação profissional. São Paulo: Fundação Jorge Duprat e Figueiredo; 2013.

19. Diretoria em Saúde do Trabalhador, Ministério da Previdência Social. Reabilitação profissional: articulando ações em saúde do trabalhador e construindo a reabilitação integral Brasília: Ministério da Previdência Social; 2013.

20. Diretoria em Saúde do Trabalhador, Ministério da Previdência Social. Reabilitação profissional: articulando ações em saúde do trabalhador e construindo a reabilitação integral - apresentação de resultados em andamento. Brasília: Ministério da Previdência Social; 2013.

21. Santos GSH, Esquerdo RL. A (in)elegibilidade de trabalhadores encaminhados ao Programa de Reabilitação Profissional do INSS. Revista Katálysis 2015; 18:151-61.

22. Ministério da Fazenda. Ata da 228a Reunião Ordinária do Conselho Nacional de Previdência Social. Brasília: Ministério da Fazenda; 2016.

23. Ministério do Desenvolvimento Social e Agrário. Reabilitação Profissional: presidente do INSS assina acordo com Fiesp/Senai em São Paulo. https://portal.inss.gov.br/reabilita cao-profissional-presidente-do-inss-assinaacordo-com-fiespsenai-em-sao-paulo/ (acessado em 08/Out/2017). 
24. Federação Nacional de Sindicatos de Trabalhadores em Saúde, Trabalho, Previdência e Assistência Social. Após pressão dos trabalhadores, governo mantém Serviço Social na nova estrutura do INSS. http://www.fenasps.org. $\mathrm{br} /$ destaque-secundario/1532-apos-pressaodos-trabalhadores-governo-mantem-servicosocial-na-nova-estrutura-do-inss (acessado em 03/Out/2017).

25. Brasil. Decreto no 8.725 , de 27 de abril de 2016. Institui a Rede Intersetorial de Reabilitação Integral e dá outras previdências. Diário Oficial da União 2016; 28 abr.

26. World Health Organization. International classification of functioning, disability and health. Geneva: World Health Organization; 2001.

27. Farias N, Buchalla CM. A classificação internacional de funcionalidade, incapacidade e saúde da Organização Mundial da Saúde: conceitos, usos e perspectivas. Rev Bras Epidemiol 2005; 8:187-93.

28. Assunção AA, Lima FPA. A contribuição da ergonomia para a identificação, redução e eliminação da nocividade do trabalho In: Mendes $\mathrm{R}$, organizador. Patologia do trabalho. Rio de Janeiro: Editora Atheneu; 2003: 1768-89.

29. Brasil. Emenda Constitucional no 95, 16 de dezembro de 2016. Altera o Ato das Disposições Constitucionais Transitórias, para instituir o Novo Regime Fiscal e dá outras providências. Diário Oficial da União 2016; 16 dez.

30. Mariano CM. Emenda Constitucional no 95/2016 e o teto dos gastos públicos: Brasil de volta ao estado de exceção econômico e ao capitalismo do desastre. Revista de Investigações Constitucionais 2017; 4:259-81.

31. Brasil. Lei no 13.341 , de 29 de setembro de 2016. Altera as Leis no 10.683 , de 28 de maio de 2003, que dispõe sobre a organização da Presidência da República e dos Ministérios, e 11.890 , de 24 de dezembro de 2008, e revoga a Medida Provisória no 717 , de 16 de março de 2016. Diário Oficial da União 2016; 30 set.

32. Brasil. Decreto no 9.003 , de 13 de março de 2017. Aprova a Estrutura Regimental e o Quadro Demonstrativo dos Cargos em Comissão e das Funções de Confiança do Ministério da Fazenda, remaneja cargos em comissão e funções de confiança e substitui cargos em comissão do Grupo-Direção e Assessoramento Superiores - DAS por Funções Comissionadas do Poder Executivo - FCPE. Diário Oficial da União 2017; 13 mar.
33. Ministério do Desenvolvimento Social e Agrário. Portaria no 414, de 28 de setembro de 2017. Aprova o regime interno do INSS e o quadro demonstrativo dos cargos em comissão e das funções de confiança do INSS. Diário Oficial da União 2017; 29 set.

34. Associação Nacional dos Participantes de Fundos de Pensão. Boletim no 566 - extinção do Ministério da Previdência sinaliza fim da política voltada para o social. http://www.anapar. com.br/?p=28429 (acessado em 06/Out/2017).

35. Thuswohl M. Previdência: mexer com ela trará danos sociais dramáticos. http://www.rede brasilatual.com.br/revistas $/ 120 /$ mexer-com -a-previdencia-trara-danos-sociais-dramati cos-3817.html (acessado em 05/Out/2017).

36. Afonso J. Extinção do Ministério da Previdência: fim da política social e solidária. https://www.brasil247.com/pt/colunistas/ jacyafonso/233258/Extin\%C3\%A7\%C3\%A3odo-Minist\%C3\%A9rio-da-Previd\%C3\%AAn cia-fim-da-pol\%C3\%ADtica-social-e-solid\% C3\%A1ria.htm (acessado em 03/Out/2017).

37. Instituto Nacional de Seguridade Social. Despacho Decisório no 3. Brasília: Instituto Nacional de Seguridade Social; 2016.

38. Instituto Nacional de Seguridade Social. Portaria no 22, de 29 de setembro de 2016. Revogar as nomeações e dispensar os servidores das áreas de reabilitação profissional e do serviço social do exercício de atividades de representantes técnicos no âmbito das Superintendências Regionais. Boletim de Serviço 2016; 30 set.

39. Instituto Nacional de Seguridade Social. Despacho Decisório no 34. Brasília: Instituto Nacional de Seguridade Social; 2017.

40. Sindicato dos Trabalhadores em Saúde e Previdência no Estado de São Paulo. Em audiência pública no Senado, servidores do Seguro e da Seguridade Social denunciam desmonte progressivo do INSS. http://www.sinsprev. org.br/sinsprev.php? editoria $=10780$ (acessado em 06/Out/2017).

41. Sindicato dos Trabalhadores em Saúde e Previdência no Estado de São Paulo. Encontro encaminha luta contra o desmonte da reabilitação profissional do INSS. http://www. sinsprev.org.br $/$ sinsprev.php? editoria $=10653$ (acessado em 06/Out/2017). 


\section{Abstract}

The field of work rehabilitation in Brazil recently incorporated changes in its underlying concepts and principles, expanding the definition of incapacity for work based on the biopsychosocial health model and adopting a territorial approach and inter-sector practices, with a view towards backing the implementation of an integrated inter-sector work rehabilitation model. However, these conceptual and normative advancements have still not been implemented in practice; they have actually come under threat from Brazil's on-going political crisis. This article discusses the current scenario in the work rehabilitation program under the Brazilian National Social Security Institute (INSS), presents the strides in the underlying theoretical premises and the concerns of work rehabilitation in the face of recent measures that reinforce the biomedical basis and the compensatory policy that led the program over the years, and signal the impending privatization of this social security service and right. The article suggests that work rehabilitation faces a scenario of uncertainties and concerns, intensified by the institutional undermining of the INSS. Rapid structural changes in the INSS and in the work rehabilitation program have undermined the gains that had promoted the initial development of a comprehensive, inter-sector work rehabilitation program aimed at healthy return to work.

Rehabilitation; Occupational Health; Social Security

\section{Resumen}

La rehabilitación profesional brasileña incorporó recientemente cambios en los conceptos y principios que la rigen. Se amplió el concepto de incapacidad, basado en el modelo biopsicosocial de salud, además de adoptarse también un enfoque territorial y prácticas intersectoriales, con el fin de proporcionar subsidios para la implementación de un modelo integrado e intersectorial de rehabilitación profesional. Sin embargo, estos avances no se profundizaron en la práctica y se encuentran amenazados ante la actual coyuntura política del país. Este artículo discute la perspectiva actual del programa de rehabilitación profesional del Instituto Nacional de Seguro Social (INSS), presenta avances en los presupuestos teóricos que lo dirigen, así como las preocupaciones a las que se enfrenta la rehabilitación profesional, en virtud de las recientes medidas que refuerzan el carácter biomédico y de política compensatoria que rigieron el programa durante el trascurso de los años, además de señalar una eminente privatización de ese servicio/derecho a la seguridad social. Se sugiere que la rehabilitación profesional vive en un panorama de incertidumbres y preocupaciones, intensificado por el proceso de debilitamiento institucional del INSS. De este modo, las rápidas alteraciones realizadas en la estructura del INSS y en el programa de rehabilitación profesional perjudicaron las conquistas que fomentaron el inicio del desarrollo de un programa de rehabilitación profesional integral $e$ intersectorial, a fin de favorecer una vuelta real $y$ saludable al trabajo.

Rehabilitación; Salud Laboral; Seguridad Social
Recebido em 17/Dez/2017

Versão final reapresentada em 21/Mar/2018 Aprocado em 06/Jun/2018 